\section{Social Desirability, Approval and Public Good Contribution}

\section{by Piers Fleming and Daniel John Zizzo}

\author{
CBESS, University of East Anglia
}

\begin{abstract}
Behaviour in public good experiments is usually attributed partly to rational self-interest and partly to social norms and preferences. This paper examines if sensitivity to social desirability affects public good contribution and in what way. A pre-experimental measure of social desirability (SDS17) was used to match partners in a two-person public good game. Half the participants received experimenter approval based upon their investment. Contrary to predictions, the highest public good investment was by low social desirability participants in the approval condition. Social desirability was not positively related to pro-social behaviour. We consider its relation to experimental and social conformity.
\end{abstract}

\section{Keywords}

Social Desirability; Experimental demand effects; Decision-making; Public goods; Conformity; Image management

\section{Correspondence to}

Piers Fleming, School of Social Work and Psychology, University of East Anglia, Norwich, NR4 7TJ, UK.

Phone +44 (0) 1603 593386, Fax: +44 (0) 1603593552 , p.fleming@uea.ac.uk.

\section{CBESS}

University of East Anglia Norwich NR4 7TJ United Kingdom www.uea.ac.uk/ssf/cbess 


\section{Introduction}

People can be self-interested, and that is in fact a starting point for a traditional economist's view of human behaviour. It is also often true; many choices can be predicted by the greatest benefit to the chooser. Perhaps more interestingly, people do not always choose the option that is of the greatest benefit to them. Some of these apparently altruistic choices can be accounted for by social norms or social preferences. In a dictator game setting, one participant (the dictator) decides how much, if any, of a sum of money to give to another participant (the receiver); participants often (over $50 \%$ of the time), choose to give some of their money to another player, even when there is no possibility of repercussion or recognition (Camerer, 2003). This behaviour is sensitive to social distance - the more likely that someone might be identified, the greater the generosity (Hoffman, McCabe and Smith, 1996). It is also potentially sensitive to experimenter demand characteristics reflecting experimental or social norms affecting behaviour (Zizzo, 2009), and this has been shown to be a likely problem in dictator games (e.g., Bardsley, 2008).

In social dilemmas such as public good contribution games, participants decide how much to contribute to a public good (say, $x$ ) that benefits everyone by some factor (say, by $0.7 \times x$ ). Self interest would predict zero contribution, because other people's benefit is at a personal cost (here the cost would be $0.3 \times x$ ), but positive contributions are normally observed (e.g., Kollock, 1998). Contribution has been found to be sensitive to disapproval, even anonymous and confidential disapproval. In some experiments, a punishment system is directly introduced, as participants can spend points to reduce the earnings of other participants after having observed public good contribution in the round; or, alternatively, subjects can just 
express social disapproval as 'disapproval points' with no monetary consequences as such (Masclet et al., 2003). It would seem that there may be a social or experimental norm to cooperate with others which supersedes a narrow view of self-interest (i.e. maximum profit within an economic game). It would also seem that this cooperative norm is sensitive to the social pressures of social distance and disapproval.

Another feature of behaviour in economic experiments (and in the real world) is that people tend to be motivated by reciprocity (e.g., Charness and Rabin, 2002). A cooperative partner should be rewarded and an uncooperative partner punished. Reciprocal behaviour in repeated public good contribution games is typically observed, as increased contribution in the previous round by the co-participants is rewarded by greater subsequent contribution and lower contribution by the coparticipants is rewarded by lower contribution (e.g., Perugini et al., 2009).

Self-interest does not exclude social considerations. However, it would appear that an understanding of individual differences in pro-social cooperation would help explain decision-making in economic settings. We chose social desirability as a likely candidate to explain at least some of the observed socially cooperative behaviour. Social desirability is the desire to present oneself in a positive light; it is typically associated with over-reporting of positive characteristics such as helpfulness and height, and under-reporting of negative characteristics such as weight or alcohol consumption (e.g., Larson, 2000). It is believed that socially desirable responding (SDR) is the result of a personality trait because it is stable over time, and that it is based on the measurement of 'need for approval' (Crowne and Marlowe, 1964). Classic work by Crowne and Marlowe (ibid) found that participants who scored highly on their measure of SDR were more likely to rate boring experimental tasks as interesting, were more likely to alter their behaviour in response to implicit positive 
reinforcement, and were more likely to agree with other participants' (incorrect) responses on perceptual judgements. These results are all evidence of conformity to the experimental situation. Crowne and Marlowe (1964) also found some evidence of conformity to social norms - high SDR participants were more likely to give common responses in word association (although not for speeded responses), and were also more likely to adhere to implicit norms in a dart-throwing task compared to low SDR participants. It seems that SDR is also important in conformity to social norms that exist outside of the experimental situation. Subsequent work has largely ignored the impact of SDR on behaviour. The work reviewed above does suggest a role for SDR in behavioural choices; however, none of the SDR experiments described above carried any significant behavioural consequences. There was no reward or cost to the behaviour; it carried no risk. However, SDR has been implicated in risk perceptions for socially unacceptable hazards (Fleming et al. 2007). This study examines whether risky behaviour with real consequences is influenced by SDR. Economic games offer well-defined paradigms for examining risky behaviour with real consequences. The public good game in particular seems to have an implicit norm of cooperation because cooperation in this game is good for the group's earnings (at the risk of an individual's own earnings). Crowne and Marlowe's (1964) work suggests that positive reinforcement is more effective than negative reinforcement on high SDR individuals and that reinforcement was most effective when it came from a person in authority. As a result, we used approval instead of disapproval and the source of approval was the experimenters, not the participants.

Based upon the social characteristics of public good contribution settings and of social desirability three predictions can be made: firstly, higher SDR should correlate with positive appraisal of hypothetical public good contribution; secondly, 
high SDR should predict greater actual public good contribution, and, finally, SDR and approval should interact with greatest contribution for the high SDR group who are given approval reinforcement.

\section{Pre-Experimental Sorting and Tax Appraisals}

\subsection{Method}

\subsubsection{Participants}

216 undergraduates $(102$ men) aged between 18 and $57(\mathrm{M}=21.6, \mathrm{SD}=$ 4.57), were recruited as part of another study (not reported here). 173 were British and all but one had English as their first language; 26 were studying Economics. Participants were paid based on their performance in the other study which took place approximately one week later.

\subsubsection{Materials}

\subsubsection{Socially Desirable Responding}

The Social Desirability Scale-17 (SDS17; Stober, 2001) consists of 16 items summed to give a total score; it is an updated version of the Marlowe-Crowne Scale (Crowne \& Marlow, 1960) and therefore measures impression management. It has been validated in the United States and Germany (Blake, Valdiserri, Neuendorf \& Nemeth, 2006). Items are responded to as True or False $(\alpha=.64$ in session 1). Test retest reliability was tested after approximately one week $(r(214)=.86, p<.001)$.

\subsubsection{Appraisal of public good - Tax}

Six single item scales were constructed to measure appraisals of public goods, see Table 1 below. Each item was responded to on a seven point scale (1: Strongly disagree: 7: Strongly Agree).

\subsubsection{Procedure}


Both the pre-experimental tasks and the main experiment were conducted over computers using z-Tree (Fischbacher, 2007) a program designed for running interactive experiments. Participants first completed the SDS17 and then the appraisal questions. Additional filler tasks were also completed.

\subsection{Results}

SDR scores correlated significantly with positive appraisals of tax payment and negatively with appraisals of tax risk. Tax benefit was unrelated to SDR (see Table 1).

$$
<<<<\text { Table } 1 \text { about here }>>>>>
$$

\section{Experiment}

\subsection{Method}

\subsubsection{Participants}

Participants from pre-experimental sorting were invited back for this experiment which took place approximately two months later. 20 participants ( 5 women, 6 economists) aged between 19 and $57(M=22.9, S D=8.29)$, from the lowest quartile of the SDS17 measure, based on Experiment 1 session data (SDS17 scores 1-5), were allocated to the low SDR group ( $\operatorname{SDS17:} M=3.2, S D=1.32) .28$ participants (12 women, 4 economists) aged between 18 and $36(M=21.3, S D=$ 4.48), from the highest quartile of the SDS17 measure (SDS17 scores 10-14) were allocated to the high SDR group (SDS17: $M=10.9, S D=1.15$ ). Participants were paid for taking part proportionately to points earned within this study. Specifically, each experimental point earned was worth 0.85 pence at the end of the experiment.

\subsubsection{Materials}

\subsubsection{Public good contribution game}


Participants had to decide how much to spend to contribute to a joint fund (the public good). For each amount $x$ invested in the public good, the public good paid out $0.7 \times x$ to both participants. Each round pairs of participants could both choose how many from 100 points to invest in the fund. The profits for the fund were divided equally between the two participants, irrespective of their contribution. For example, if participant A contributed 100 points and participant B contributed 0 points, the fund would be worth 140 points; participant A and B would then receive 70 points each from the fund. That round participant A would have made 70 points and participant $B$ would have made 170 points. After both players had decided, they were given feedback on their partner's investment and their current earnings. There were 10 rounds, and subjects were matched with the same partners throughout the 10 rounds.

\subsubsection{Procedure}

Pairs of participants sorted by condition took part in the research in separate booths with a computer terminal. Participants were aware that their decisions would have real monetary consequences. Each participant was paired with one partner for the duration of the experiment. Partners were allocated by approximately matched SDS17 scores. Half of the pairs were randomly allocated to an approval feedback condition; these participants were given feedback in the form of approval points from the experimenter based upon an algorithm using their previous round's investment. Approval was exponentially higher for greater previous round investment ( 0 for 0 points, least approval; 4 for 50 points; 10 for 100 points, most approval). Approval feedback had no impact on payment received and was communicated to playing partners prior to the next round's investment. 10 rounds of investment were played with the same partner. In total the experiment took less than one hour. 


\subsection{Results}

A 2 (Social Desirability: high, low) $\times 2$ (Approval: present, absent) by 10 (Rounds) mixed ANOVA was run with participant investment (for each round) as the DV. There were effects of round $F_{(9,396)}=15.54, p<.001$, partial $-\eta^{2}=.261$; social desirability $F_{(1,44)}=5.40, p=.025$, partial $-\eta^{2}=.109$ and interactions between approval and social desirability $F_{(1,44)}=9.21, p=.004$, partial $-\eta^{2}=.173$; round and social desirability $F_{(9,396)}=3.60, p<.001$, partial $-\eta^{2}=.076$ and round, approval and social desirability $F_{(9,396)}=6.41, p<.001$, partial $-\eta^{2}=.127$. No other effects reached significance at the .05 level. Figure 1 illustrates the two-way interaction between social desirability and approval. Figure 1 indicates that the interaction and main effect of social desirability are the result of substantially greater investment in the low social desirability, approval group. The other groups show similar (lower) investment. Figure 2 illustrates the effects by round. Contrasts were performed comparing high and low social desirability, and approval (present or absent) for each subsequent round with first round investment. The contrasts revealed no significant differences for rounds 2 and 10 but rounds 3 to 9 were all significantly different $(F>4)$. Using Figure 2 we can see that the three-way interaction is the result of additional investment by the low social desirability, approval-present group during rounds 3-9.

$<<<<$ Figures 1 and 2 about here $>>>>>$

Reciprocity was measured by averaging within-subjects Spearman's correlations between own investment each round and the partner's previous round investment. Mean correlations were $M=.30$ (high SDR groups, approval absent); $M=$ .49 (high SDR, approval present); $M=.36$ (low SDR approval absent); $M=.40$ (low SDR, approval present). Sign tests revealed that as a whole the within subject correlations were significantly different from zero $(p=.0001)$. However, by 
experimental condition only the high SDR, approval-present group were significantly different from $0(p=.012)$.

\section{Discussion}

While participants' hypothetical appraisals of public goods were in line with predictions, their actual behaviour was not. The interaction between social desirability and approval shows that, in fact, participants in the low social desirability group responded to approval with increased public good contribution.

Hypothetical appraisals of tax showed attitudes consistent with a social norm of tax payment. Most people pay taxes, thus funding, among other things, public goods such as healthcare and education. Higher social desirability scores were associated with increased conformity (payment of tax) and reduced concern about the behaviour of others eligible to pay tax (reduced risk, worry and regret of others' payment). We can conclude that the public good of tax payment is a social norm and that stated conformity to the social norm is associated with social desirability. This extends to confidence in the tax system, but not to perceptions of taxes as beneficial. There are two explanations for this association between SDR and stated appraisal of tax payment. Firstly, people high in social desirability are more sensitive to social norms, perhaps by greater awareness or greater conformity; therefore, they are more likely to realise that a socially accepted attitude or behaviour is expected and to behave in accordance. Alternatively, awareness may be equal but people high in SDR may have a greater willingness to adjust their responses to present themselves in a more socially acceptable way despite having the same underlying beliefs as those low in SDR in terms of actual benefits from taxes. Either way, the expected behaviour associated with this social norm was found. 
While cooperation, as elicited from stated responses, conforms to a social norm, it seems not be reflected in increased behavioural cooperation by participants high in SDR. This could suggest a dissociation between verbal and behavioural cognitive mechanisms (Zizzo, 2003). An alternative or complementary explanation is to suggest that SDR is simply a measure of self-presentation. By this account, selfinterest in a situation with behavioural and monetary consequences outweighs a desire to present a positive image. However, individual differences in SDR did have an (unexpected) effect on behaviour; the low SDR group were able to behave cooperatively (and profit) in the approval condition when the high SDR group could not.

The results by round offer an explanation (see Figure 2). There was no first round difference between the groups; at this point no feedback had been received and so experimenter approval was unknown (although it was known that approval would be awarded). Given that there was no behavioural difference between the groups for round 1, but that there was an association between SDR and tax appraisal, it seems that there is no selective effect of the cooperative norm (or SDR alone) on public good game behaviour; social desirability does not mean pro-social. The most obvious explanation is that public good games are not an ecologically valid proxy for taxes. Taxes have associated social values and context which the public good game does not. The evidence from the second and subsequent rounds is revealing; high SDR, approval feedback participants steadily increased investment whereas the other groups did not. This can be explained by another aspect of social desirability. Marlowe and Crowne's (1964) work found that SDR was associated with conformity both to social norms and also to local, experimental norms including agreement with confederates' perceptual judgements. As noted earlier, and found in our experimental data, public 
good behaviour is characterised by reciprocity: a strong predictor of subsequent round's investment is a partner's previous round investment. People high in SDR were more closely conforming to their partner's behaviour (as evidenced by withinsubjects correlations) and so, once the experiment had begun and experimental norms were established, they would have been less likely to diverge from the within experiment conformity. This is supported by the particularly high measure of reciprocity for the high-SDR, approval group. By contrast, participants low in SDR were willing to diverge from their partner's previous investment in the presence of approval information. Once established, this divergence becomes a virtuous circle as increased cooperation leads to increased gains and self-interest and cooperation become aligned.

Future research could re-examine the role of SDR in other economic settings, and the additional effect of establishing explicit experimental norms prior to the experiment. It would also clearly be interesting to run a public good contribution experiment in a tax payment frame and see whether this would be sufficient to establish a closer connection between responses to tax payment questions and public good contribution. The evidence on the significance of a tax payment frame, as emerging from behavioural tax payment games, has been mixed so far (Baldry, 1986; Alm et al., 1992).

Our broad conclusion is that, while social desirability matters, the way it matters subtly depends on the social desirability personality type, and this in turn affects the social and experimental perceptions of what is demanded. Social desirability is important as a measure of conformity, and not as an indicator of prosocial behaviour, at least in public good contribution settings. However, that measured conformity can be either local to the experimental situation or related to wider social 
norms. In this experiment local conformity was more important to behaviour, but this could well be an artefact of this particular experimental design. Authority and cues matter, but they do not necessarily matter in ways that are easy to predict. This is a more general potential problem insofar as it makes the job of team design and operations management in organisations more difficult, insofar as behavioural responses to social demands are still limitedly understood. A better understanding of the specific circumstances and the tensions between local and wider social norms is needed for those predictions to be accurate. Clearly, considerably more research on the relationship between personality types, social desirability and economic behaviour is needed. 


\section{Acknowledgements}

Thanks to the Nuffield Foundation for part-funding this research (SGS/35859) with the University of East Anglia. Thanks to Kei Tsutsui for his research assistance. Thanks also for advice and encouragement to presentations at the Subjective Probability, Utility and Decision Making conference, Rovereto (Italy), and at the University of East Anglia, where versions of this work were presented. Experimental instructions for this research can be found online at Daniel John Zizzo's homepage (http://www.uea.ac.uk/ ec601/). 


\section{References}

Alm, J., McClelland, G.H. \& Schultze, W.D. (1992). Why do people pay taxes?

Journal of Public Economics, 48, 21-38.

Baldry, J. C. (1986). Tax evasion is not a gamble. Economics Letters, 22, 333-335.

Bardsley, N. (2008). Dictator game giving: Altruism or artefact? Experimental

Economics, 11, 122-133.

Blake, B.F. Valdiserri, J., Neuendorf K.A. \& Nemeth, J. (2006). Validity of the SDS17 measure of social desirability in the American context, Personality and Individual Differences, 40, 1625-1636.

Camerer, C.F. (2003). Behavioral Game Theory: Experiments in Strategic

Interaction. Princeton University Press: Princeton NJ.

Charness, G. \& Rabin, M. (2002). Understanding social preferences with simple tests, Quarterly Journal of Economics, 117, 817-869.

Crowne, D. P. \& Marlowe, D. (1960). A new scale of social desirability independent of psychopathology, Journal of Consulting Psychology, 24, 349-354.

Crowne, D. P. \& Marlowe, D. (1964). The Approval Motive, New York: John Wiley \& Sons.

Fischbacher, U. (2007). z-Tree: Zurich toolbox for ready-made economic experiments, Experimental Economics, 10, 171-178.

Fleming, P., Townsend, E., Lowe K.C. \& Ferguson, E. (2007). Social desirability effects on biotechnology across the dimensions of risk, ethicality and naturalness. Journal of Risk Research, 10, 989-1003.

Hoffman, E., McCabe, K. \& Smith, V.L. (1996). Social distance and other-regarding behavior in dictator games. American Economic Review, 86, 653-60. 
Kollock, P. (1998). Social dilemmas: The anatomy of cooperation. Annual Review of Sociology, 24, 183-214.

Larson M.R. (2000) Social desirability and self-reported weight and height.

International Journal of Obesity, 24, 663-665.

Masclet, D., Noussair, C., Tucker, S. \& Villeval, M.C. (2003). Monetary and nonmonetary punishment in the voluntary contributions mechanism. American Economic Review, 93, 366-380.

Perugini, M., Tan, J.H.W. \& Zizzo, D.J. (2009). Which is the more predictable gender? Public good contribution and personality. Economic Issues, in press.

Stober, J. (2001). The social desirability scale-17 (SDS17): Convergent validity, discriminant validity, and relationship with age. European Journal of Psychological Assessment, 17, 222-232.

Zizzo, D.J. (2003). Verbal and behavioral learning in a probability compounding task. Theory and Decision, 54, 287-314.

Zizzo, D.J. (2009). Experimenter demand effects in economic experiments.

Experimental Economics, in press. 
Single-item appraisal measure

$\rho \quad p$

I would be likely to pay my share of tax

$.190 \quad .005$

I believe that the average UK person would be likely to pay their share

$.189 \quad .005$

I believe paying tax is risky

$-.245<.001$

I believe tax is beneficial

$-.024 \quad .731$

I would worry about other people not paying their share

$-.202 \quad .003$

If most other people did not pay their share I would regret paying my share

$-.156 \quad .021$ 


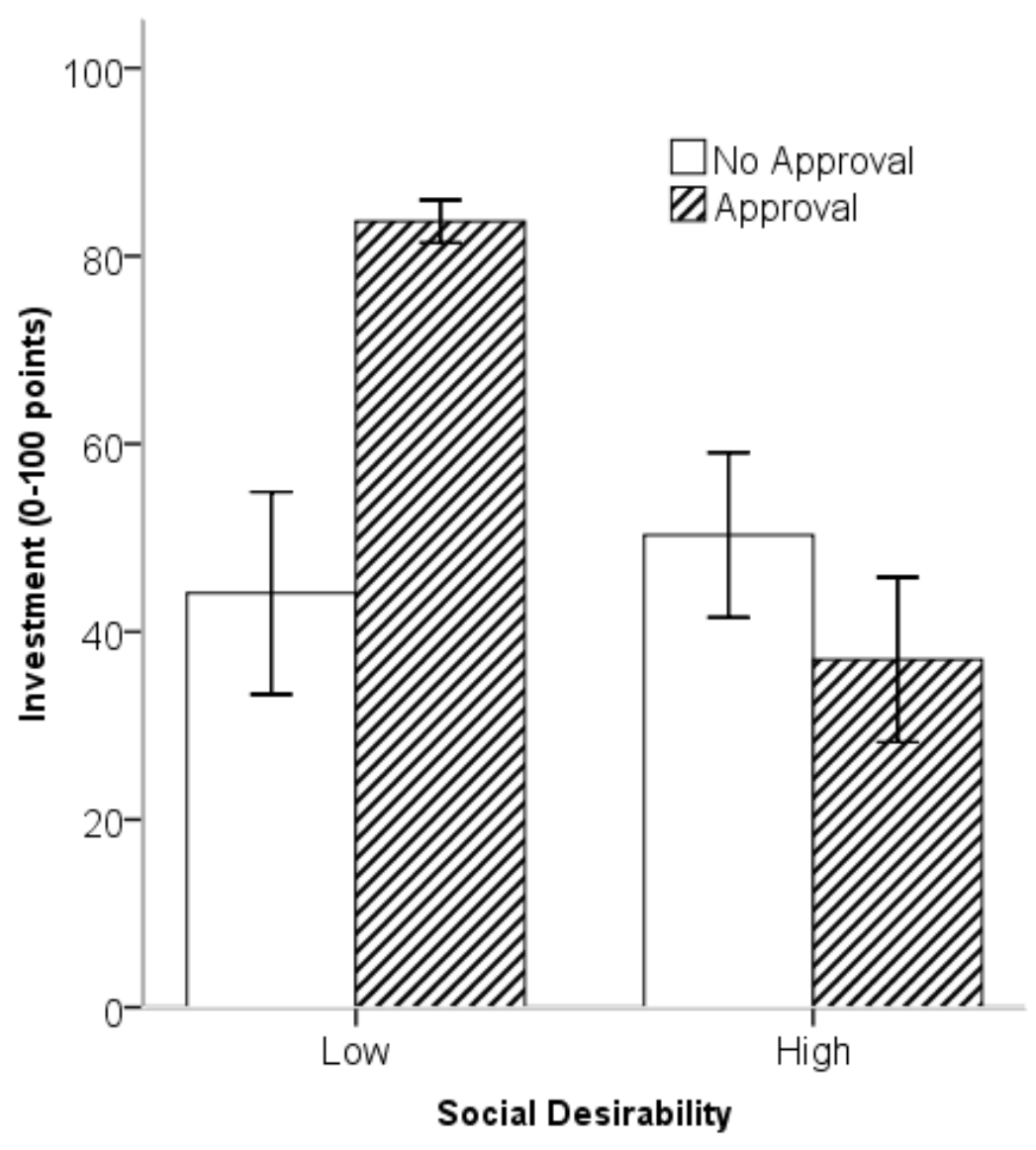




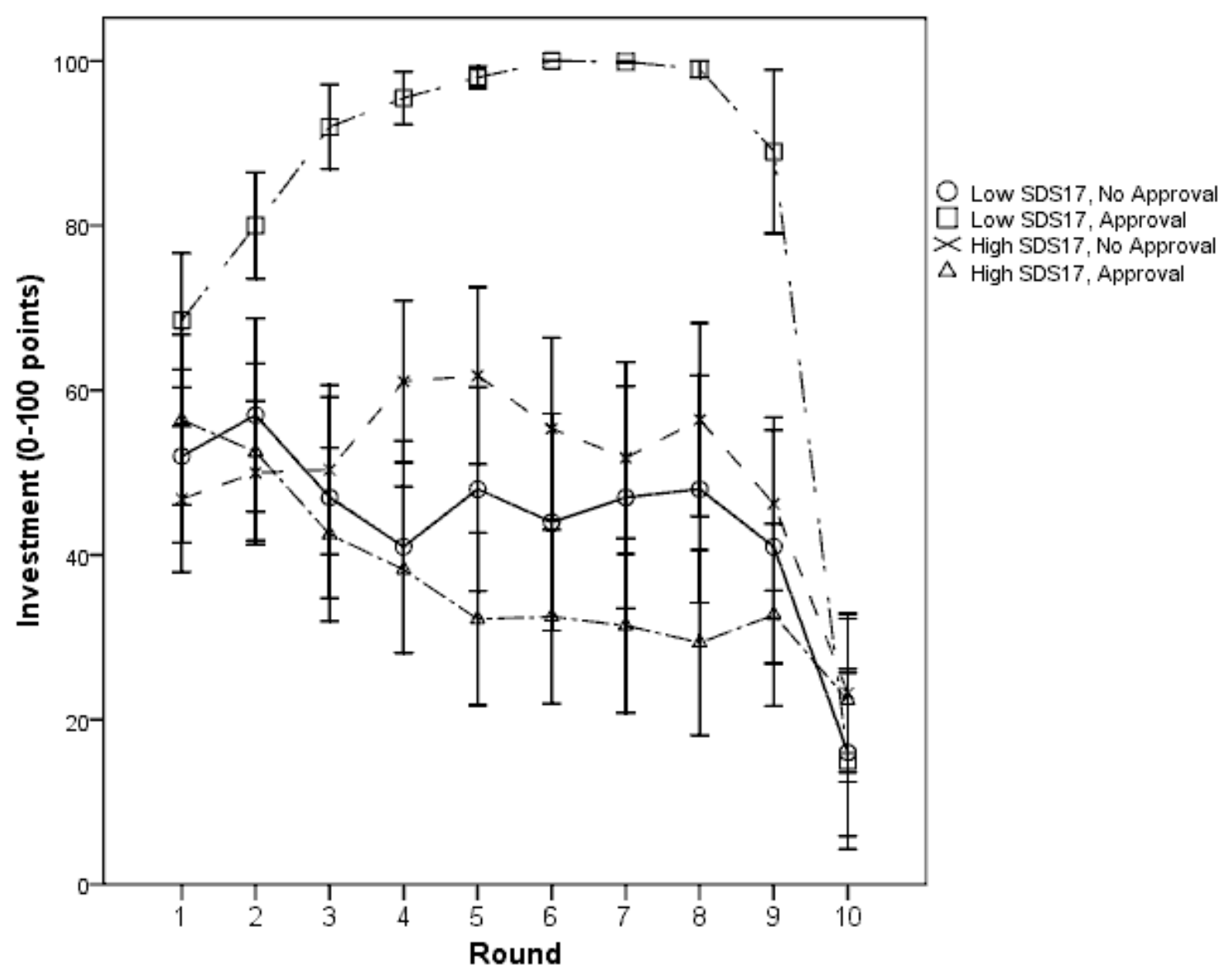


Table 1. Spearman rank order correlation coefficients $(\rho)$ and $p$ (two-tailed) between appraisal items and SDS17

Figure 1. Mean Investment across 10 rounds $(+/-S E)$ for Low and High Social Desirability groups in Approval Feedback and No Approval Feedback conditions.

Figure 2. Mean investment by round (+/-SE) for Low and High Social Desirability groups in Approval Feedback and No Approval Feedback conditions. 